\title{
Publisher Correction: Marine microbiology: A day in the life of marine sulfonates
}

Beth T. Williams and Jonathan D. Todd (B)

Correction to: Nature Microbiology https://doi.org/10.1038/s41564-019-0576-5, published online 20 September 2019.

In this News \& Views originally published the wrong version of Fig. 1 was used. In panel a, the blue 'coA' label should have been 'CoA', the arrow pointing from 'Cysteate' to 'Sulfolactate' should have been double-headed, in the yellow shaded region the blue curved arrow should have been double-headed and the structures at the bottom should have been labelled 'Phytoplankton'. In panel b, the purple phytoplankton structure should have been green, and the label 'Sulfonates:' should have been sitting above the label 'Cysteate.' The figure has now been replaced. 


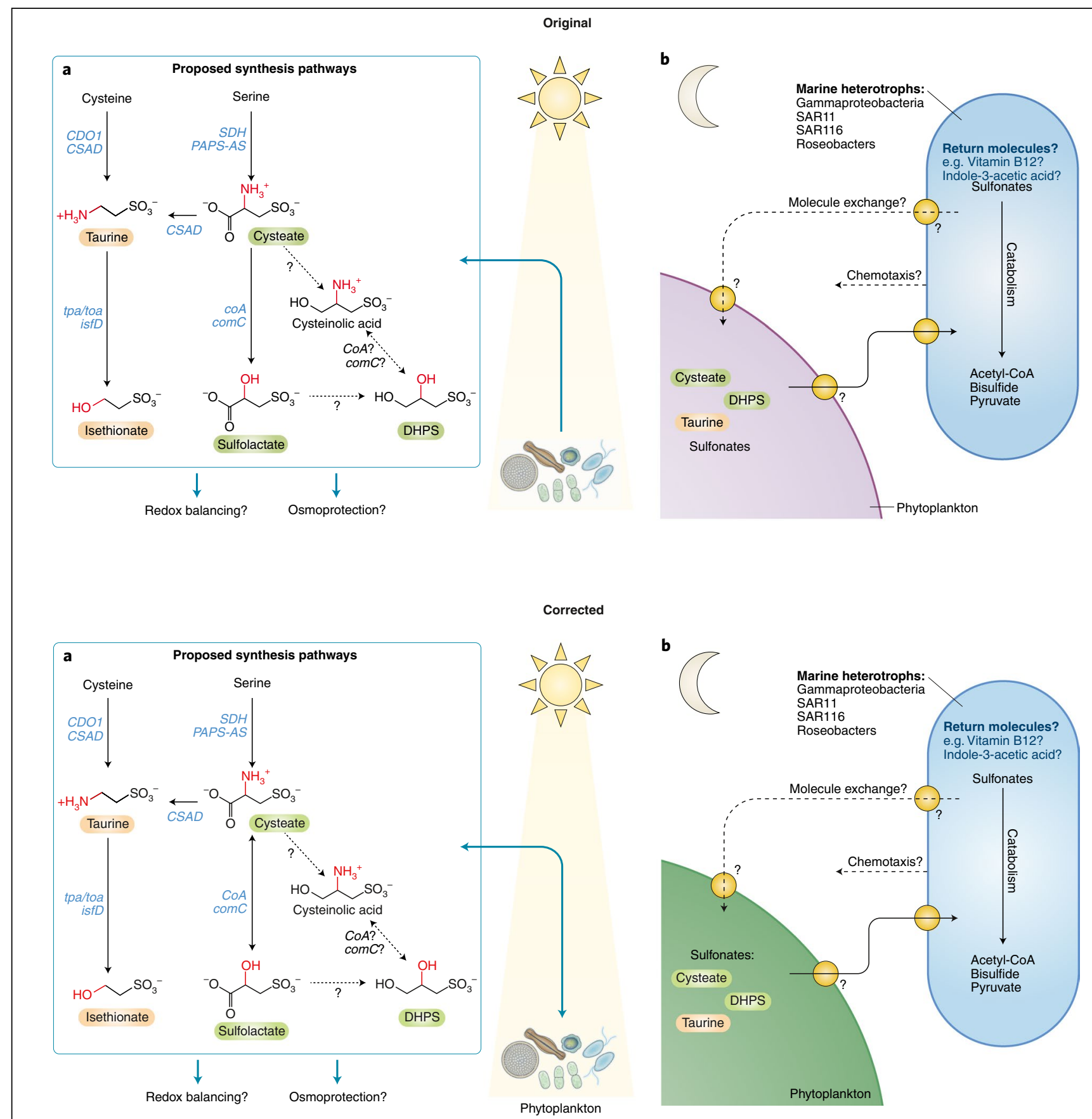

Fig. 1 | Original and corrected.

Published online: 18 October 2019

https://doi.org/10.1038/s41564-019-0606-3 